\title{
ПЕРВЫЕ ДАННЫЕ ПО КРИОТЕРМОМЕТРИИ ФЛЮИДНЫХ ВКЛЮЧЕНИЙ В НЕФЕЛИНЕ ЛОПАРИТОВОГО МЕСТОРОЖДЕНИЯ ЛОВОЗЕРСКОГО ЩЕЛОЧНОГО МАССИВА
}

\section{Мокрушина О.Д.}

Геологический институт КНЦРАН, Anamumbl, artmok@yandex.ru

Ловозерский массив входит в группу наиболее крупных щелочных интрузий мира и занимают центральное место в составе Кольской провинции, представленной палеозойскими щелочными и щелочно-ультраосновными интрузиями с карбонатитами. Массив сложен щелочными породами трех комплексов - дифференцированного лопаритоносного, эвдиалитовых луявритов и жильных пород. Наиболее широко распространенным является дифференцированный комплекс, составляющий примерно $3 / 4$ изученной части массива, в пределах которого находится главный рудный объект массива - Ловозерское лопаритовое месторождение. Рудная минерализация обычно приурочена к границам между массивными (фойяитами, уртитами) и трахитоидными (луявритами) породами. Для большинства рудных горизонтов характерно устойчивое и непрерывное лопаритовое оруденение [2].

Объектом исследования были флюидные включения, находящиеся в нефелине среднезернистых мезократовых луявритов рудного горизонта I-4 Ловозерского редкометального месторождения (рудник Карнасурт). Индивидуальные флюидные включения изучены методами микротермометрии и КР-спектроскопии в лаборатории термобарогеохимии Института геологии и минерологии СО РАН (г. Новосибирск). Термобарогеохимические исследования флюидных включений проводились на измерительном комплексе, состоящем из термокамеры THMSG-600 с измеримым диапазоном температур от -196 до $+600^{\circ} \mathrm{C}$ (точность данных замораживания и температуры гомогенизации $\pm 0.1{ }^{\circ} \mathrm{C}$ и $\pm 1^{\circ} \mathrm{C}$, соответственно), микроскопа с набором длиннофокусных объективов, видеокамеры и управляющего компьютера. КР-спектры в интервале от 100 до $4000 \mathrm{~cm}^{-1}$ были получены с использованием спектрометра T64000 Horiba Jobin Yvon.

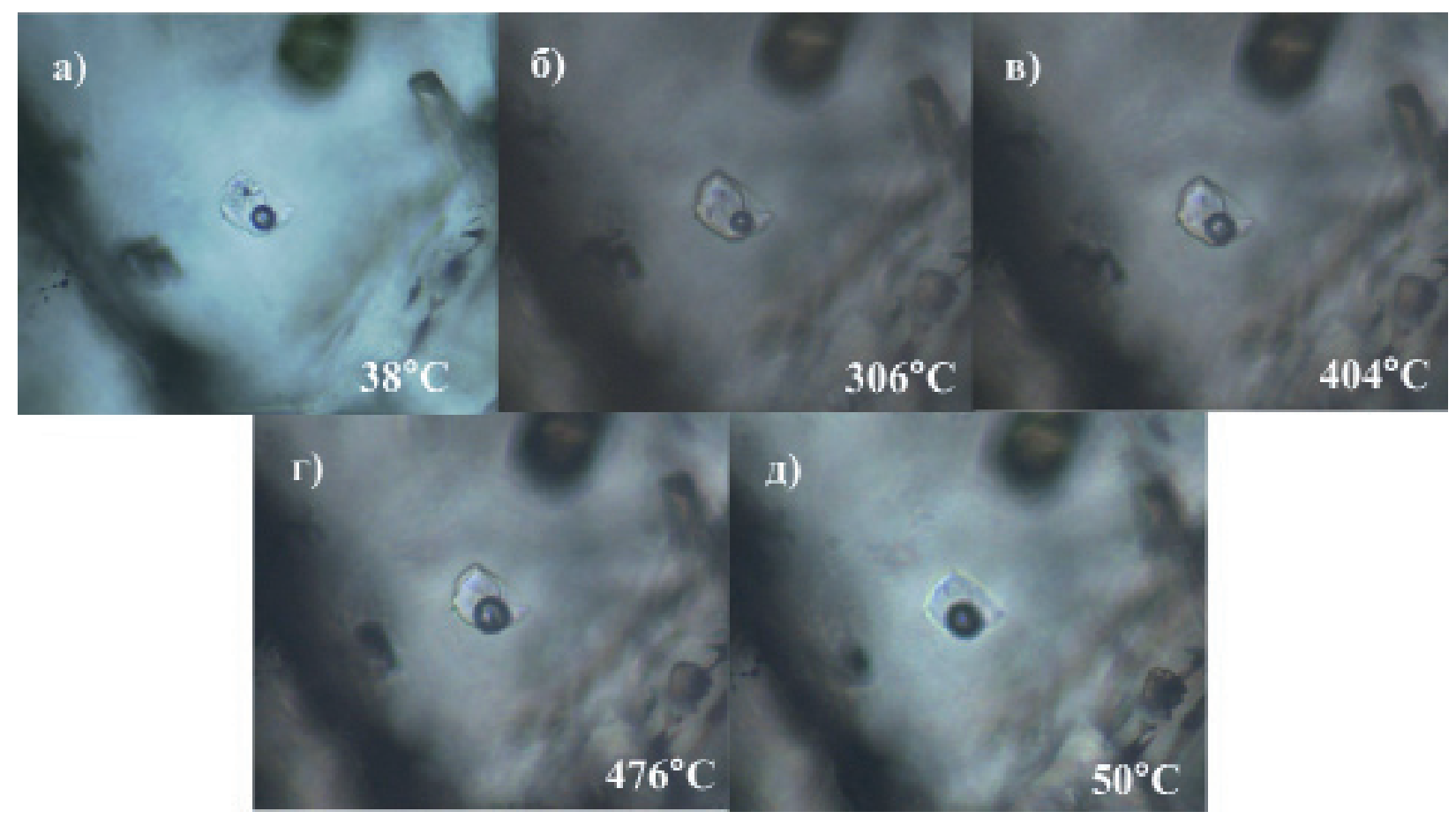

Рис. 1. Фазовые превращения в ходе эксперимента по гомогенизации флюидного включения.

а) отчетливо видны все фазы включения; б) газовый пузырек уменьшился в размере, растворились крупные кристаллические фазы; в) размер газового пузырька увеличивается; г) исчезают мелкие кристаллические фазы, газовый пузырек продолжает увеличиваться в размере; д) увеличенный размер газового пузыря после эксперимента. 

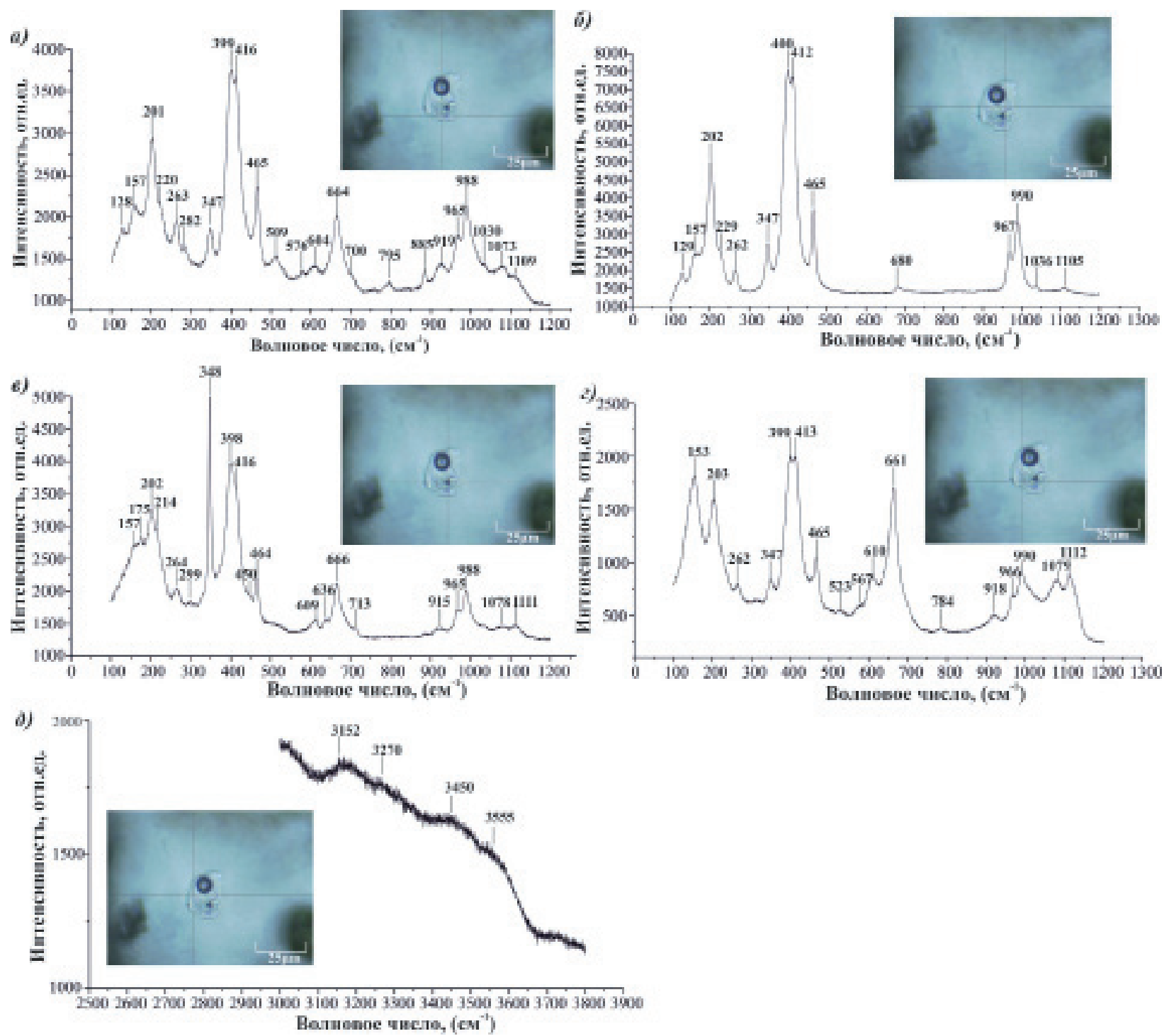

Рис. 2. КР-спектры дочерних минералов (а-г) и жидкой фазы (д) флюидного включения в нефелине.

При оптическом изучении образцов по взаимоотношениям фаз, форме и морфологическим признакам были отобраны наиболее подходящие для дальнейшего исследования инструментальными методами включения. Вакуоли различной формы, содержат газ, жидкость и от двух до четырех кристаллических фаз. Размер включений составляют от 10 до 50 мкм. Выбранные включения представляют собой первичные кристаллофлюидные включения гомогенного захвата.

В ходе экспериментов по криометрии флюидных включений фазовых переходов не наблюдалось во всем диапазоне отрицательных температур криотермокамеры. Отсутствие в газовом пузыре твердых фаз даже при охлаждении до $-196^{\circ} \mathrm{C}$, вероятнее всего, говорит о том, что он содержит смесь газов, состоящую из $\mathrm{CH}_{4}$ и $\mathrm{H}_{2}$. Подобное поведение газовой фазы при проведении криометрических исследований было описано в работе Дж. Поттер для включений в луяврите Ловозерского массива содержащих $\mathrm{CH}_{4}$ и до 40 мол.\% $\mathrm{H}_{2}$ [5]. Преобладающие содержание данных газов в этих же породах установлено методами газовой хромотографии и КР-спектрометрии в работах Л.Н. Когарко и В.А. Нивина $[1,4]$.

Жидкая фаза включений, также не претерпевшая превращений при охлаждении до температуры $-196^{\circ} \mathrm{C}$, предположительно, представляет собой водный раствор, насыщенный алюмосиликатами натрия и калия.

При проведении экспериментов по термометрии полной гомогенизации включения достигнуто не было (рис. 1). При температуре $38^{\circ} \mathrm{C}$ внутри включения хорошо просматриваются газовый 
пузырек и несколько кристаллических фаз разного цвета, размера и формы (рис. 1 а). При повышении температуры до $300^{\circ} \mathrm{C}$ газовый пузырек уменьшается в объеме, но не исчезает. При температуре от 300 до $310^{\circ} \mathrm{C}$ растворяются наиболее крупные кристаллические фазы, одновременно с этим газовый пузырек начинает увеличиваться в объеме (рис. 1 б, в). В температурном интервале от 420 до $440^{\circ} \mathrm{C}$ исчезают оставшиеся мелкие кристаллические фазы (рис. 1 г). Газовый пузырь при достижении максимальной температуры эксперимента $\left(500^{\circ} \mathrm{C}\right)$ увеличился, примерно, в три раза относительно своего первоначального объема. Увеличенный объем газового пузыря сохраняется и после окончания эксперимента при полном остывании (рис. 1 д). При понижении температуры до $110^{\circ} \mathrm{C}$ мелкие кристаллические фазы образовались вновь, более крупные - не кристаллизовались.
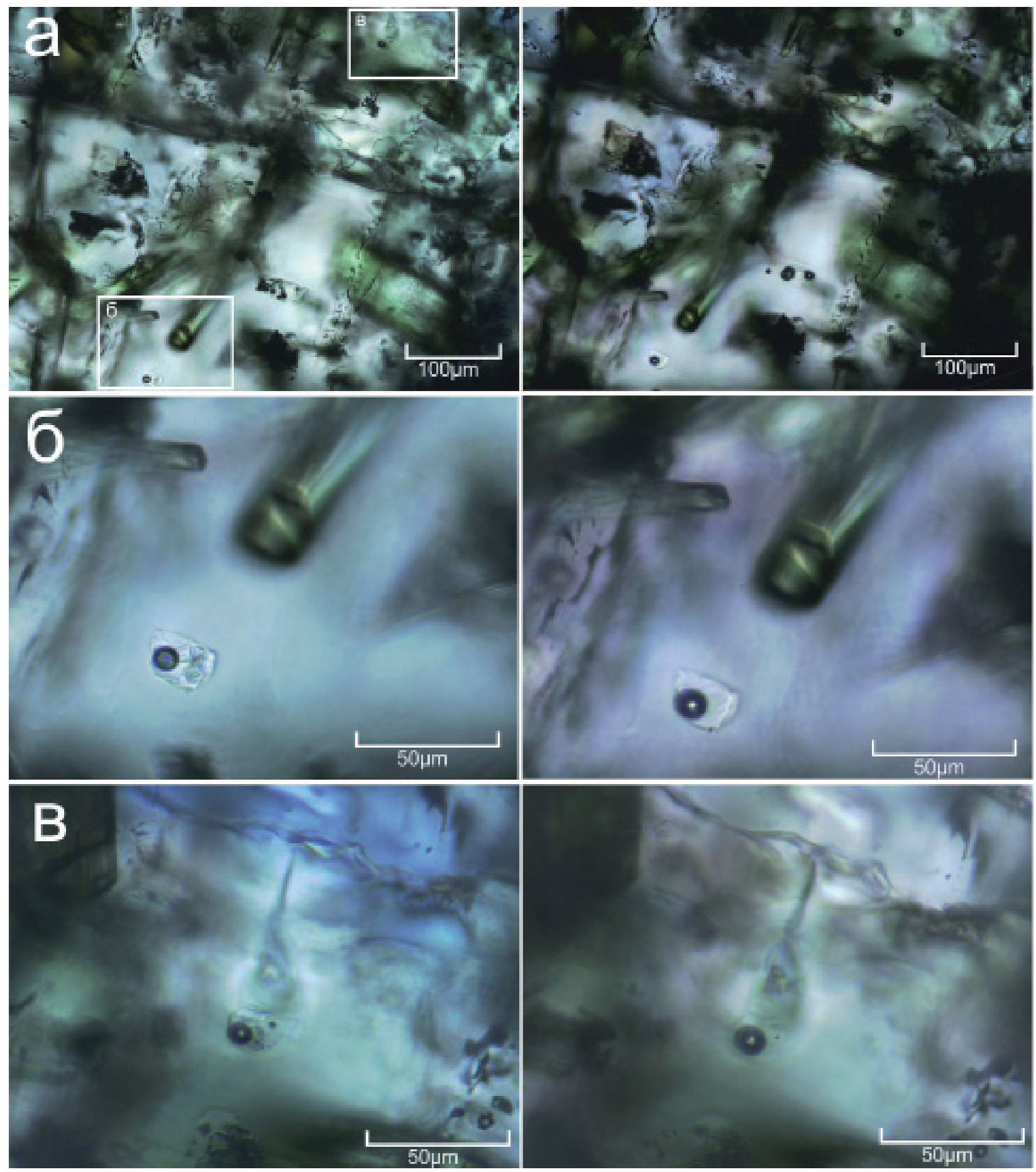

Рис. 3. Флюидные включения в нефелине до (слева) и после (справа) проведения термометрических экспериментов. 
КР-спектроскопия проводилась для жидкой и твердых фаз флюидных включений в нефелине (рис. 2). КР-спектры жидкой фазы (рис. 2 д) имеют пики в диапазоне от 3150 до $3600 \mathrm{~cm}^{-1}$, характерные для воды. По сравнению с минералом хозяином, нефелином, спектрограммы дочерних минералов включения имеют дополнительные пики при 220, 296, 416, 509, 661-666, 915-919, 1032, 1073, $1079 \mathrm{~cm}^{-1}$. Пики 210, 508, $1032 \mathrm{~cm}^{-1}$ характерны для альбита; 296, $416 \mathrm{~cm}^{-1}$ - для содалита; 661, 664, 666 $\mathrm{cm}^{-1}$ - для магнетита и диаспора. В числе дочерних минералов включения (рис. 3 б) можно определить нефелин по характеристическим пикам 202, 347, 399, 412, 415, 465 и 988 см$^{-1}$.

На рисунке 3 показаны различные флюидные включения в нефелине до (слева) и после (справа) проведения термометрических экспериментов. Содержимое вакуолей включений представлено схожим набором фаз, и при проведении эксперимента характеризуется близкими температурными значения фазовых переходов, что говорит об их генетическом родстве. Во флюидных включениях, содержащих более одного газового пузыря, на протяжении всего эксперимента пузырьки не объединяются, что указывает на высокую вязкость жидкой фазы.

Полученные в ходе термобарогеохимических исследований данные позволяют нам сделать вывод о том, что изученные включения в нефелине представляют собой первичные кристаллофлюидные включения гомогенного захвата с большим разнообразием твердых фаз, характерные для магматических щелочных пород, в которых они являются включениями остаточных расплавоврассолов и высококонцентрированных растворов, образующихся на заключительной стадии кристаллизации в результате обогащения остаточных силикатных расплавов солевыми, газовыми и жидкими компонентами.

Исследования выполнены в рамках Госзадания ГИ КНЦ РАН (№ 0231-2015-0009).

\section{Литература}

1. Когарко Л.Н., Костольяни Ч., Рябчиков И.Д. Режим флюидной фазы щелочных магм. Новосибирск, Наука. Сибирское отделение. 1988. С. 41-50.

2. Пожиленко В.И., Гавриленко Б.В., Жиров Д.В., Жабин С.В. Геология рудных районов Мурманской области. Под ред. Ф.П. Митрофанова, Н.И. Бичука. Апатиты. КНЦ РАН. 2002. 359 с.

3. Толмачева Е.В., Великославинский С.Д. Термобарогеохимические исследования при региональногеологических исследованиях и геологосъемочных работах с общими поисками в областях развития докембрия. Методические рекомендации. СПб. 1999. 115 с.

4. $\quad$ Nivin V.A., Belov N.I., Treloar P.J., Timofeyev V.V. Relationships between gas geochemistry and release rates and the stressed state of igneous rock massifs // Tectonophysics. 2001. V. 336 (1-4). P. 233-244.

5. Potter J., Rankin A.H., Treloar P.J. Abiogenic Fischer-Tropsch synthesis of hydrocarbons in alkaline igneous rocks; fluid inclusion, textural and isotopic evidence from the Lovozero complex, N.W. Russia // Lithos. 75(3-4). 2004. P. 311-330. doi:10.1016/j.lithos.2004.03.003. 